\title{
Dealing with patent ductus arteriosus (PDA) spasm in the cath lab
}

\begin{abstract}
Introduction: Catheter- closure of the PDA is among the safest interventional cardiac procedures, but rarely, the patent ductus has been found to close intermittently, because of the patent ductus arteriosus (PDA) spasm during the PDA closure by cath. Spasm may result in failure of the procedure, or under-sizing of the device, So it is important to correlating echocardiographic findings with the angiographic measurement.
\end{abstract}

Objective: To present cases of spasm of the patent ductus arteriosus during transcatheter closure which we depended on the echocardiographic measurement to choose the size of the device for PDA closure

Cases Relate: Case 1: 11 months old girl was admitted for PDA device closure.

Echocardiography showed: PDA $4 \mathrm{~mm}$ with left to right shunt

Aortic angiography at the beginning of the cath showed that the PDA had completely disappeared, After waiting a few minutes the angiography showed $3 \mathrm{~mm}$ PDA, It was decided that to close the PDA with amplatzer ADO II occluder device, and successfully closed.

Case 2: 16-monthold boy undergoing transcatheter coil occlusion of a patent ductus arteriosus. Ductus arteriosus spontaneous spasm with subsequent relaxation resulted in inadvertent coil embolization.

This case report and review of the literature have implications for transcatheter treatment of persistent ductus arteriosus.

Conclusion: Correlation the echocardiographic size of the PDA with the angiographic measurement should be taken to avoid device under-sizing when PDA spasm occurs during the catheterization.

Keywords: patent ductus arteriosus, spasm, cardiac catheterization, ductal spasm, coil embolization
Volume II Issue 3 - 2018

\author{
Ahmed Alkamali,' Samah Alasrawi ${ }^{2}$ \\ 'Consultant Pediatric Cardiology,Alqassimi Children's and \\ Women Hospital, UAE \\ ${ }^{2}$ Specialist Pediatric Cardiology,Aljalila Children`s Heart Center,
} UAE

Correspondence: Ahmed Alkamali, Consultant Pediatric Cardiology, Alqassimi Children's and Women Hospital, Sharjah, UAE,Tel 00971506278987, Email aalkamali@hotmail.com

Received: May I, 2018 | Published: May 242018

\section{Introduction}

The ductus arteriosus is known to close functionally within hours after birth in full-term infants, and it usually closes anatomically within 2 to 8 weeks. ${ }^{1}$ In premature infants, complete closure of the ductus may be delayed until 6 months of age, ${ }^{2}$ whereas in rare instances closure may not occur until adult life. ${ }^{3}$ Catheter $\square$ closure of the PDA is among the safest of interventional cardiac procedures and is considered the procedure of choice among infants $\geq 4 \mathrm{~kg} .{ }^{4}$

Very rarely, the patent ductus has been found to close intermittently, because of the patent ductus arteriosus (PDA) spasm during the PDA closure by cath. Spasm may result in failure of the procedure, undersizing of the device, so we presented this case which also emphasizes the importance of correlating echocardiographic findings with the angiographic measurement when choosing the appropriate device size during transcatheter closure of a patent ductus arteriosus. We report our experience with 2 case referred for occlusion of A PDA in whom ductal spasm complicated the procedure.

\section{Case report}

\section{Case I:}

11 months old girl was admitted to our hospital for PDA device closure. She was born pre-term 26 weeks, kept in the NICU for 2 months and on Respiratory support for one month, The diagnosis of a patent ductus arteriosus had been made after birth. Ibuprofen was given and started on Lasix for the first 7 months of age then stopped.

On examination: The child was of normal size and appearance without cyanosis. Her blood pressure within normal limits, Pulsations were equal in all extremities. A continuous murmur Grade 3/6 intensity was best heard on the upper left sternal border

Electrocardiogram was judged to be within normal limits for her age, and her chest roentgenogram showed only slightly increased pulmonary vascularity (Figure 1).

Echocardiography showed: PDA $4 \mathrm{~mm}$ with left to right shunt (Figure 2).

Angiography at the beginning of the cath showed that the PDA had completely disappeared (Figure 3).

After waiting a few minutes the angiography showed PDA $2 \mathrm{~mm}$, with length $9 \mathrm{~mm}$ (Figure 4).

A catheter was easily passed percutaneously through the femoral vein into the pulmonary artery and aorta through the PDA. It was decided that to close the PDA with amplatzer ductal occluder type 2 size 4 by $6 \mathrm{~mm}$, and successfully closed (Figure 5) (Figure 6). 


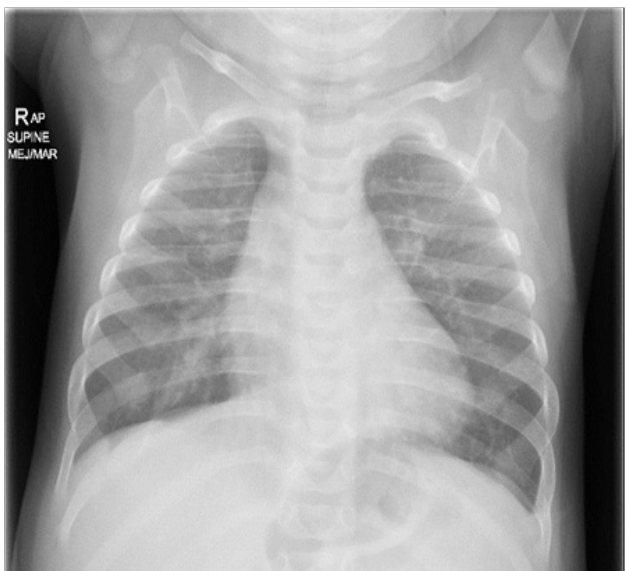

Figure I Chest XR showed slightly increased pulmonary vascularity.

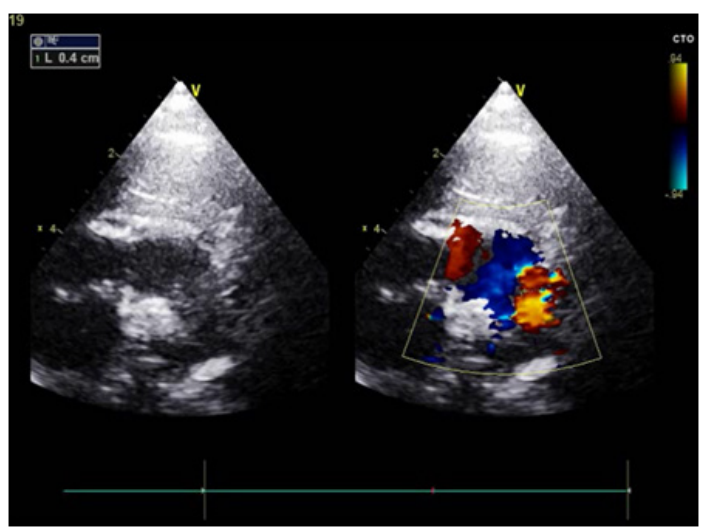

Figure 2 Short axis view Echocardiogram showed the size of the PDA.

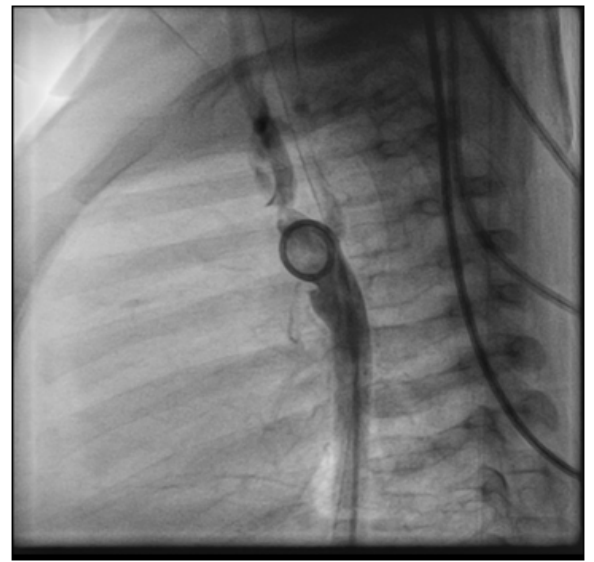

Figure 3 Angiogram in the Aorta showed that the PDA disappeared.

\section{Case 2:}

A 16-month-old boy, born at 27 weeks of gestation, part of the twin was referred for coil occlusion of his PDA. One month prior to cardiac catheterization, loud continuous murmur grade $3 / 6$ was present at the left upper sternal border and his echocardiogram demonstrated at that time moderate size PDA left to right shunt.

The day prior to cardiac catheterization, echocardiography showed Tiny PDA (Figure 8).

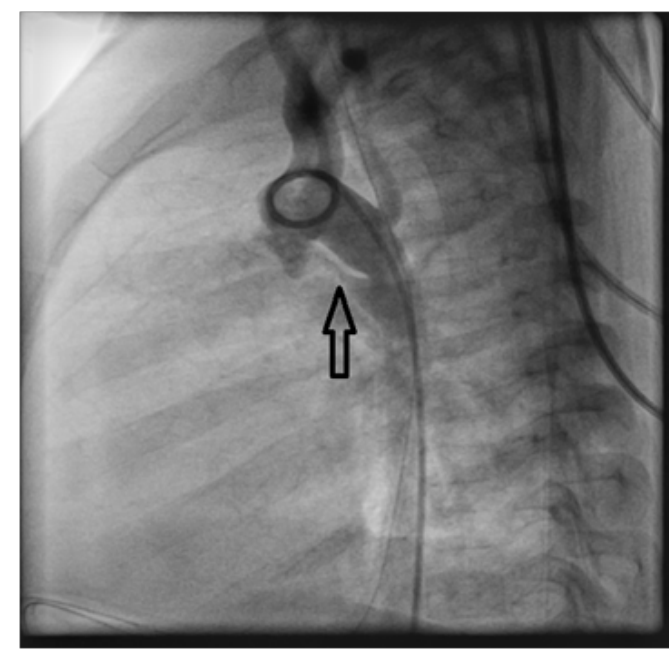

Figure 4 Angiogram showed the PDA (black arrow).

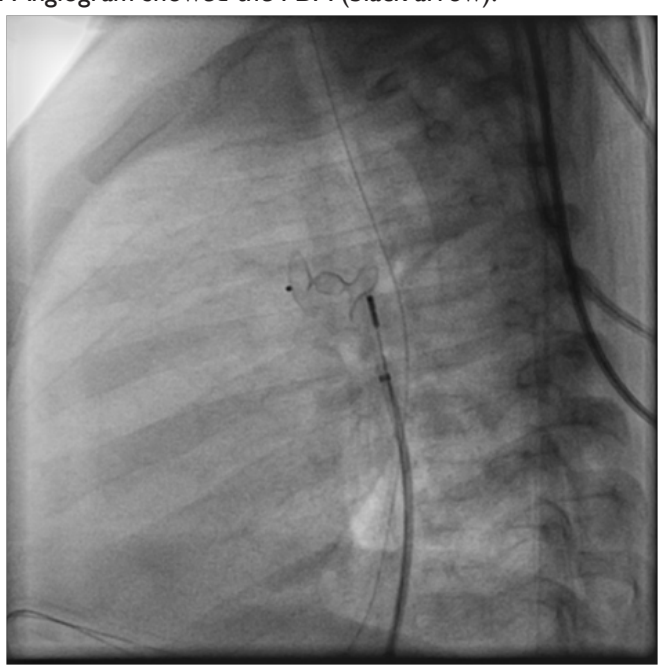

Figure 5 Angiogram:The device closed the PDA.

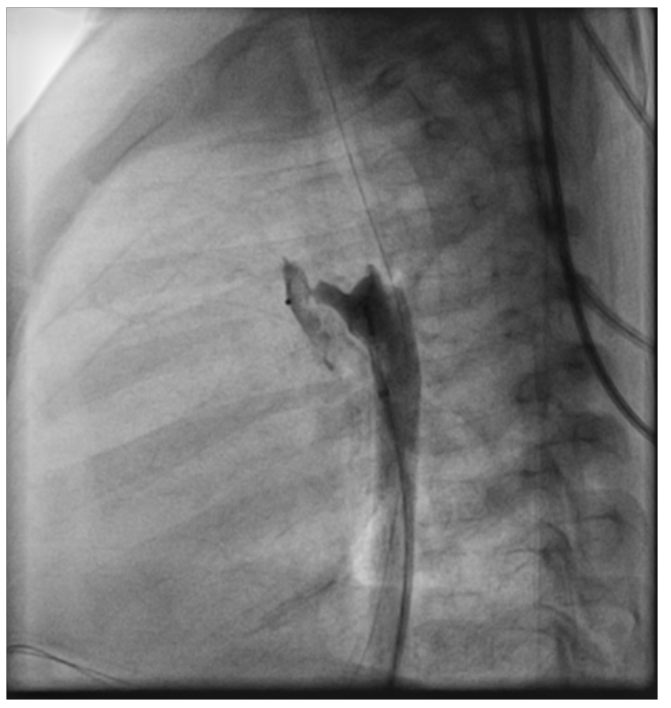

Figure 6 Angiogram: suitable device size without any leak. 


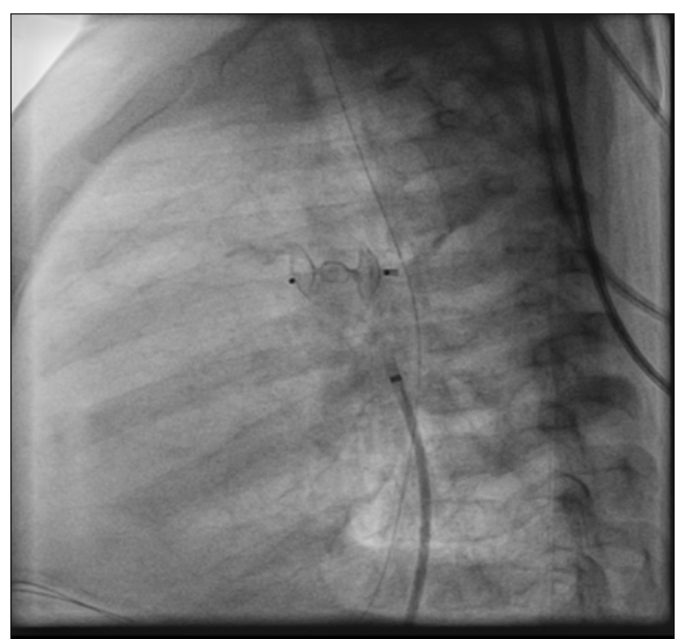

Figure 7 Angiogram: successful PDA device closure.

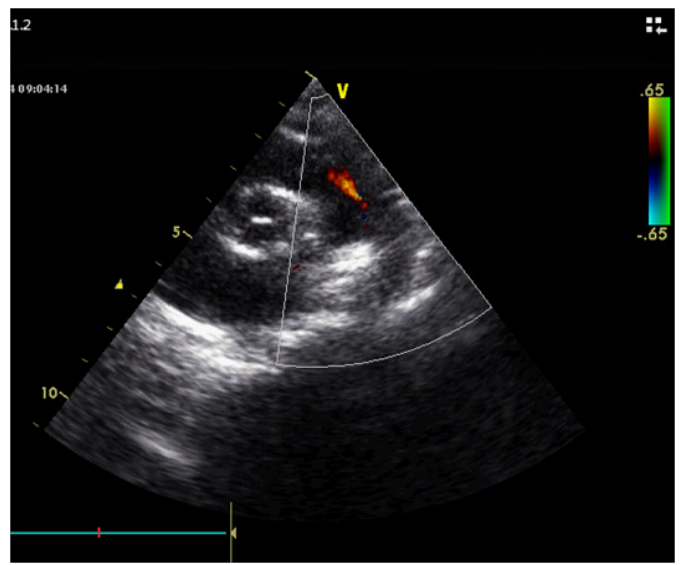

Figure 8 Echocardiograph, short axis view showed tiny PDA.

It was decided that he will undergo coil occlusion of the ductus arteriosus because his anatomy was found to be favorable for transcatheter closure.

Under GA, Cardiac cathtrization done. Angiogram of aorta showed tiny PDA (Figure 9).

The PDA was not crossed with wire or catheter and the PDA narrowest diameter was $1 \mathrm{~mm}$. Flipper Cook coil $3 \mathrm{~mm}$ by 4 was delivered through $4 \mathrm{~F}$ multipurpose catheter and deployed in the ductus arteriosus successfully. Follow up angiography demonstrated there was a residual flow around the coil. After short time, the coil embolized to right pulmonary artery. Snare was introduced and the coil was snared out successfully without complications. Then $6.5 \mathrm{~mm}$ by 4Flipper Cook coil was delivered. After deployment, an angio test confirmed that the coil was in a good position. There was minimal residual leak around the coil. Several minutes later, the coil was embolized to the left pulmonary artery, again snare was re-introduced. There was difficulty to retrieve the coil at the level of tricuspid valve. Then it was brought down till groin, but could not be snared out. Cardiac surgeon did cut down and coil removed without major complications repeated aortic angiogram was done showed large tubular PDA about 4mm (Figure 10).

Left femoral vein was cannulated and 7Fdelivery sheath introduced. PDA amplatzer duct occluder $6 \mathrm{mmx} 8 \mathrm{~mm}$ delivered and closed the PDA successfully. Follow up angiogram showed minor leak through the device (Figure 11).

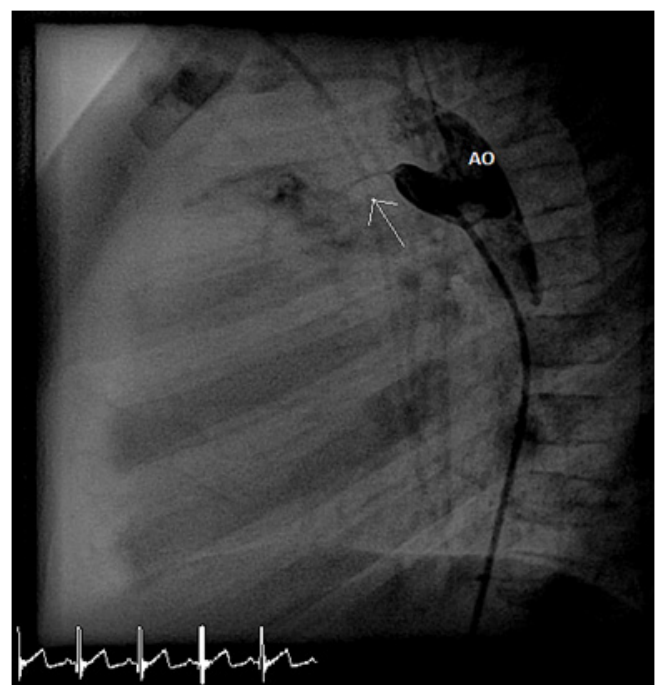

Figure 9 Angiogram:Tiny PDA.

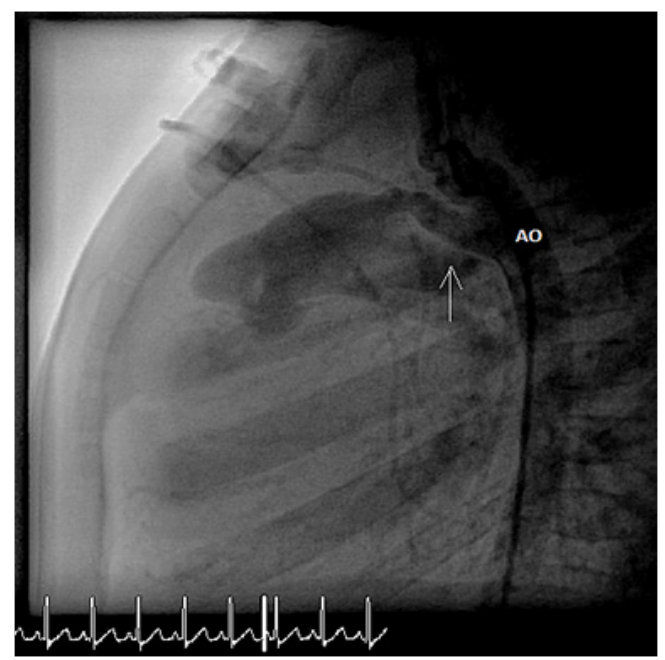

Figure 10 Angiogram: Large PDA.

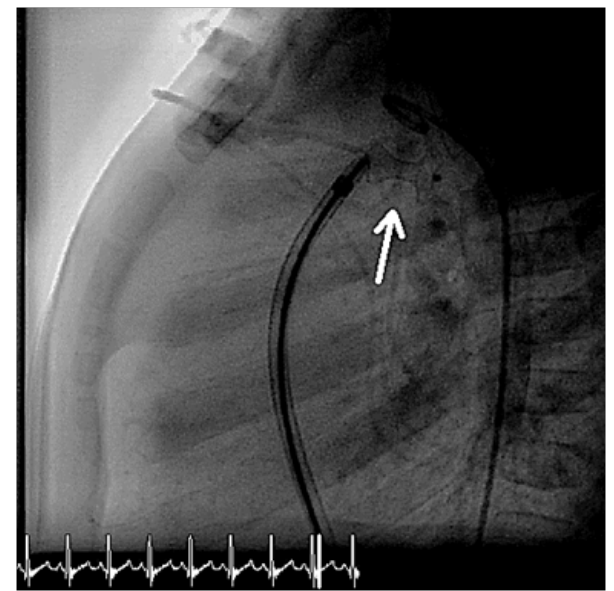

Figure I I Angiogram: Device in place. 
Post cardiac catheterization child was hemodynamically stable. Echocardiogram done next day revealed no residual leak, device in proper position with laminar flow in pulmonary artery and aortic arch and good peripheral pulses present in both legs.

\section{Discussion}

Transcatheter occlusion of the PDA has developed into an important form of treatment with excellent results. It obviates the need for surgical intervention for this defect. ${ }^{4}$ However, a problem in transcatheter occlusion of a patent ductus arteriosus in infants is its potential to spasm. Ductal spasm is a rare yet important complication of device occlusions of patent ductus arteriosus. Spasm may result in failure of the procedure, under-sizing of the device, or embolization of the implanted device as the spasm resolves after the procedure. ${ }^{5,6}$ Some operators are concerned about this that they avoid any attempt to enter the PDA before angiography. ${ }^{7}$ As we saw in our case 1 that the PDA appeared again when we waited a few minutes.

Even without manipulation, there have been reports of spontaneous spasm of the PDA that led to improper selection of device..$^{8-10}$ In our patient, the angiogram was inconsistent with the echocardiographic measurement at the beginning. So the selection of the device size based on the echocardiogram.

One of the risks of PDA coil occlusion is inadvertent coil embolization as we saw in the second case, reported in up to $15 \%$ of patients undergoing this procedure. ${ }^{11,12}$ One reason for this relatively high incidence of coil embolization may be subtle degrees of vascular reactivity of the ductus arteriosus that allow coil migration with ductal relaxation

It is therefore important to correlate the echocardiographic evaluation of the size of the PDA with the angiographic measurement when choosing the appropriate device and size during transcatheter closure of a patent ductus arteriosus. Inappropriate device selection can lead to embolization of the device and additional transcatheter or surgical procedures for the patient.

\section{Conclusion}

Spasm of the patent ductus arteriosus can occurs during transcatheter closure and may be an unrecognized cause of procedural failure. So correlation the echocardiographic evaluation of the size of the PDA with the angiographic measurement and care should be taken to avoid device under-sizing when spasm occurs.

\section{References}

1. Moss AJ, Emmanoulides GC, Duffie ER Jr. Closure of the ductus arteriosus in the newborn infant. Pediatrics. 1963;32:25-30.

2. Mitchell SC. The ductus arteriosus in the neonatal period. J Pediatr. 1957;51(1):12-17.

3. Campbell M. Natural history of persistent ductus arteriosus. Br Heart J. 1968;30:4-13.

4. Pass RH, Hijazi Z, Hsu DT, et al. Multicenter USA Amplatzer patent ductus arteriosus occlusion device trial: initial and one-year results. $J \mathrm{Am}$ Coll Cardiol. 2004;44(3):513-9.

5. Kumar, RK. "Patent ductus arteriosus: coil occlusion." Percutaneous Interventions for Congenital Heart Disease, Ed. Horst Sievert, Ed. Shakeel A. Qureshi, Ed. Neil Wilson, Ed. Ziyad M Hijazi. Oxon: Informa Healthcare, 2007. 385-401.

6. Rohit MK, Garg PK, Kumar N, et al. Spontaneous Intermittent Closure of Patent Ductus Arteriosus in a Three-Year-Old Child: Angiographic Documentation. Congenital Cardiology Today. 2008;6(6):1,2-4.

7. Francis J. More on coil closure of PDA (patent ductus arteriosus).

8. Tzifa A, Tulloh R, Rosenthal E. Spontaneous spasm of the arterial duct: a pitfall for transcatheter occlusion. Heart. 2005;91(1):31.

9. MacDonald ST, Bhindi R, Ormerod O, et al. Ductus arteriosus spasm. JACC Cardiovasc Interv. 2009;2(1):73.

10. Spasm of the patent ductus arteriosustranscatheter closure of the PDA.

11. Hosking MC, Benson LN, Musewe N, et al. Transcatheter occlusion of the persistently patent ductusarteriosus:forty-month follow-up and prevalence of residual shunting. Circulation. 1991;84(6):2313-2317.

12. Latson LA. Residual shunts after transcatheter closure of patent ductus arteriosus: a major concern or benign "techno-malady"? Circulation. $1991 ; 84(6): 2591-2593$. 